\title{
Fiddler crabs and their above-ground sedimentary structures: a review
}

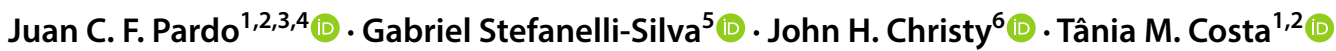

Received: 14 November 2019 / Accepted: 24 March 2020 / Published online: 13 April 2020

(c) The Author(s) 2020

\begin{abstract}
Fiddler crabs are abundant, semi-terrestrial crustaceans inhabiting tropical, subtropical and warm temperate coasts worldwide. Some species build above-ground sedimentary structures at or near the opening to their burrows. The functions and shapes of these constructions vary interspecifically and according to the sex of the builder. Here, we compile the dispersed reports on these structures, suggest uniform naming for different shapes, review explanations for their functions and explore associations between the attributes of builders and their structures. We found that 47 fiddler crab species build at least one type (or subtype) of structure, including chimneys, hoods, pillars, semidomes, mudballs, and rims. Sedimentary structures show a strong association with sediment type as well as builder front type, genus and sex, but not with fiddler crab clade. Experimental studies have revealed distinct, sometimes multiple functions for some of these structures (e.g., female attraction, reduction of aggressive behavior and/or landmark orientation); however, most studies have been observational leaving the proposed functions of these structures for many species untested. Both field and laboratory experiments as well as observational studies can help us to better understand these sedimentary structures and their role in fiddler crab behavior and ecology.
\end{abstract}

Keywords External structures $\cdot$ Burrow $\cdot$ Chimney $\cdot$ Hood $\cdot$ Pillar $\cdot$ Semidome $\cdot$ Mudball $\cdot$ Rim

Juan C. F. Pardo

pardojcf3@gmail.com

1 Laboratório de Ecologia e Comportamento Animal (LABECOM), Instituto de Biociências, Universidade Estadual Paulista 'Júlio de Mesquita Filho' (UNESP), Campus do Litoral Paulista, Praça Infante Dom Henrique, Parque Bitaru, São Vicente, SP 11380-972, Brazil

2 Programa de Pós-Graduação, Ciências Biológicas (Zoologia), Instituto de Biociências, Universidade Estadual Paulista 'Júlio de Mesquita Filho' (UNESP), Campus de Botucatu, Rua Prof. Dr. Antônio Celso Wagner Zanin, 250, Distrito de Rubião Junior, Botucatu, SP 18618-689, Brazil

3 Center for Coastal Research (CCR), University of Agder (UiA), 4604 Kristiansand, Norway

4 Norwegian Institute for Water Research (NIVA), Jon Lilletuns vei 3, 4879 Grimstad, Norway

5 Laboratório de Ecologia e Evolução de Mar Profundo (LAMP), Universidade de São (USP), Instituto Oceanográfico, Praça do Oceanográfico, 191, Butantã, São Paulo, SP 05508-120, Brazil

6 Smithsonian Tropical Research Institute, Balboa-Ancón 0843-03092, Panamá

\section{Introduction}

Many animals build structures: ants and termites construct nests and underground galleries, beavers build dams, spiders weave webs, and so forth (Hansell 2007). Some structures have obvious benefits for their builders (e.g. shelter, display and ornamentation), yet the functions of many other structures remain unclear (Hansell 2007). Structures are regularly and appropriately viewed as physical manifestations of the behavioral phenotypes of builders (Dawkins 1982; Schaedelin and Taborsky 2009; Bailey 2012). When such constructions result from manipulation of the sediment in the form of tracks, burrows or pellets, they are called biogenic sedimentary structures, defined by Frey (1973) as "[a product of] the activity of an organism upon or within an unconsolidated particulate substrate".

Fiddler crabs build biogenic above-ground sedimentary structures from mud or sand, sometimes more than one type per species, in or just above the intertidal zone (Crane 1975; Wolfrath 1992; Thurman et al. 2013; Mokhtari et al. 2015). There are 106 described species (102 living, 4 extinct), encompassing eleven genera and two subfamilies within Ocypodidae (Gelasiminae and Ocypodinae) (Rosenberg 2001; Shih et al. 2016). The group is distributed worldwide 
(Crane 1975; Rosenberg 2001) and is subdivided in two major clades, Atlantic-East Pacific (AEP) and Indo-West Pacific (IWP), estimated to have undergone differentiation around 17 million years ago (Sturmbauer et al. 1996; Shih et al. 2016).

The structures built by fiddler crabs are diverse in form and are built via different behaviors. Some are built only by males, others by females, and the social and ecological contexts in which they are built vary within and among species. Not surprisingly, there are several hypothesized functions for these structures. The most thoroughly and experimentally tested idea is that the relatively tall structures some courting males build by their burrows attract females because they elicit landmark orientation, i.e., the tendency of fiddler, ghost and related crabs, when away from their burrows, to move toward vertical objects to reduce their conspicuousness to predators and thereby reduce their predation risk (summarized by Christy and Wada 2015). Yet, recent experimental studies on other species showed that the attractive properties of a similar structure are sex- and context dependent, which challenges the claim that such structures elicit a common, shared and ancestral behavioral response (Kim et al. 2017). Far less well-studied are the structures built by female fiddler crabs and their possible functions. In this paper, we compile the dispersed reports on sedimentary structures built by fiddler crabs, suggest uniform naming for different shapes, and review and update explanations for their functions.

\section{Literature survey and data analysis}

Ethological studies have described and proposed functions for fiddler crab above-ground biogenic structures since the early twentieth century (see Yamaguchi et al.'s 2005 discussion for details). Among the most comprehensive studies, Crane (1975) described fiddler crab constructions as structures "erected beside the burrows, made of substrate" and classified them as three main shapes: chimneys, pillars and hoods. von Hagen (1968) highlighted that 12 fiddler crab species build structures, followed by Christy (1988a) who tallied a total of 14 species. Christy et al. (2001) then stated that at least 19 species construct sedimentary structures out of sand or mud including hoods, pillars, semidomes, and rims (or lips); subsequently, 20 chimney builders were identified by Shih et al. (2005) and 10 semidome builders were compiled by Carvalho et al. (2018).

Our review of the current literature found that at least 47 fiddler crab species ( 9 genera) build above-ground sedimentary structures (Table 1). We employed a narrative literature review strategy aimed to encompass all published literature on the topic: periodic searches from September 2014 to August 2019 using the term "fiddler crab" combined with “chimney", "hood", "shelter", “oven", "pillar”, “dome”, "semi-dome", "semidome", "mudball", "rim", "lip", "above-ground structure" or "sedimentary structure" were performed using the ISI Web of Science and Google Scholar. Searches were followed by checking the reference list of papers for any possible missing studies. Seventy-six relevant papers on the topic were found (Table 1).

We employed a multiple correspondence analysis (MCA), used to identify patterns and associations of categorical variables (Greenacre and Blasius 2006), to explore relationships between descriptive categories of above-ground structure, sediment type, builder clade, genus, sex and front (i.e., width between the bases of eyestalks) (categories and data are specified in Table 1). Function of sedimentary structures was not included due to a lack of experimental data for some structures, including multifunctionality, which can lead to misinterpretation of MCA results. Sedimentary structures with vague and uncertain descriptions were also not included (all indicated with a '?' in Table 1). Mixed sediments were categorized according to their predominant sediment type (sand for muddy sand; mud for sandy mud) to simplify data interpretation. Additionally, a Chi-Square test followed by Cramer's $V$ test, a measure of association for categorical variables, was performed to correlate types (subtypes) of sedimentary structures with the above-mentioned variables. The likelihood ratio (95\% confidence interval) was assumed when the chi-square assumption was violated (McHugh 2013).

\section{Types (and subtypes) of sedimentary structures: what is known?}

Four types and two subtypes of above-ground sedimentary structures were recognized: chimney (Fig. 1a, 26 species); hood (or shelter/oven) (Fig. 1b, 11 species), further categorized into pillar (Fig. 1c, 6 species) and semidome (Fig. 1d, 11 species); mudball (Fig. 1e, 5 species); and rim (or lip) (Fig. 1f, 4 species). All fiddler crab genera, except for Petruca and Cranuca, represented by Petruca panamensis (Stimpson, 1859) and Cranuca inversa (Hoffmann, 1874), respectively, build at least one type of sedimentary structure (Fig. 2).

\section{Chimney}

Chimneys (also called funnels by Salmon 1987) are tall, tower-shaped structures with vertical walls that completely encircle the burrow entrance (Fig. 3a). The construction process is similar for all male and female builders (Table 1): crabs stack mud/muddy sand at the edge of the burrow entrance using their pereiopods and chelipeds (Shih et al. 2005; Gusmão-Junior et al. 2012). The source of chimney material is varied; some chimney builders use sediment dug 


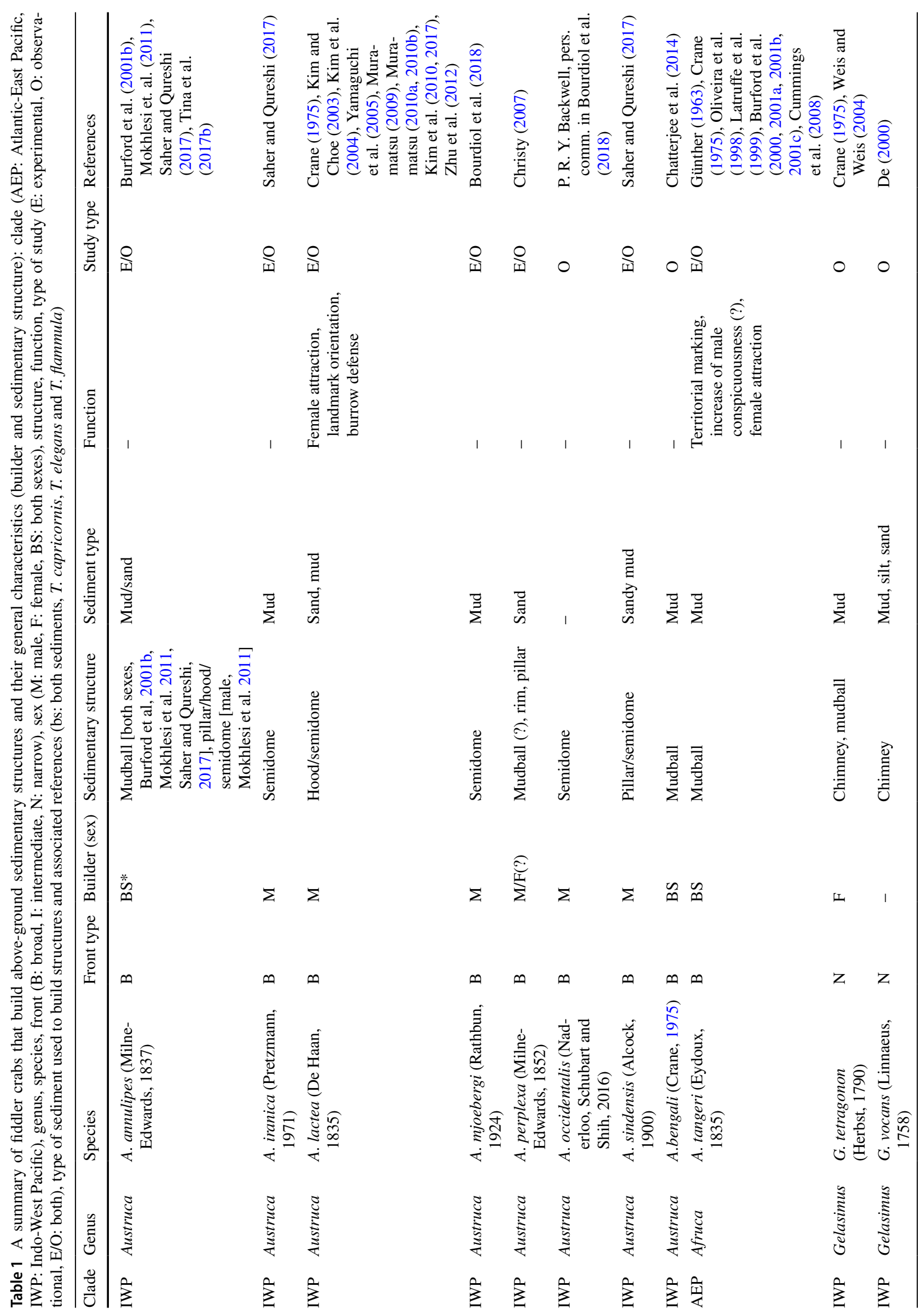




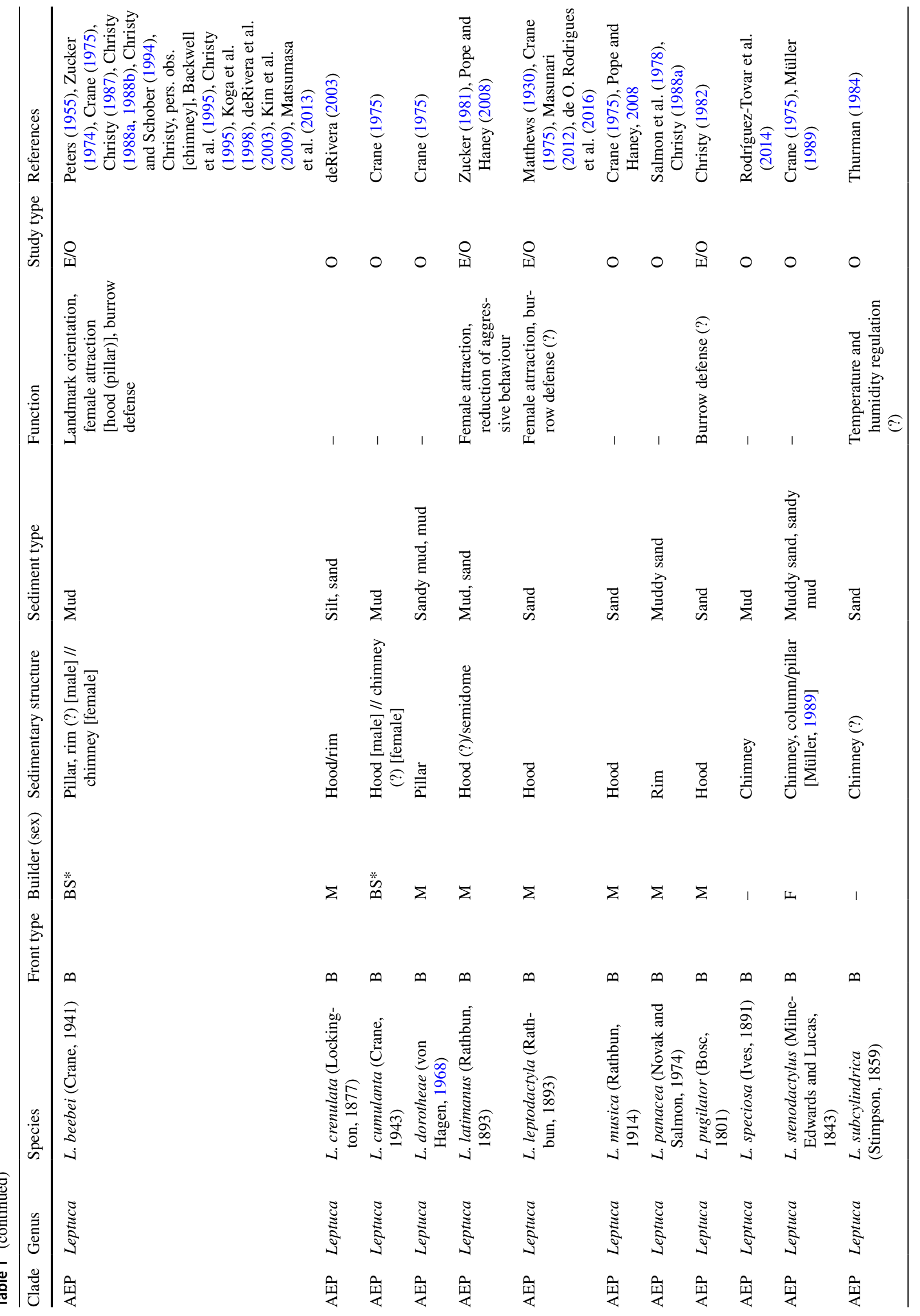




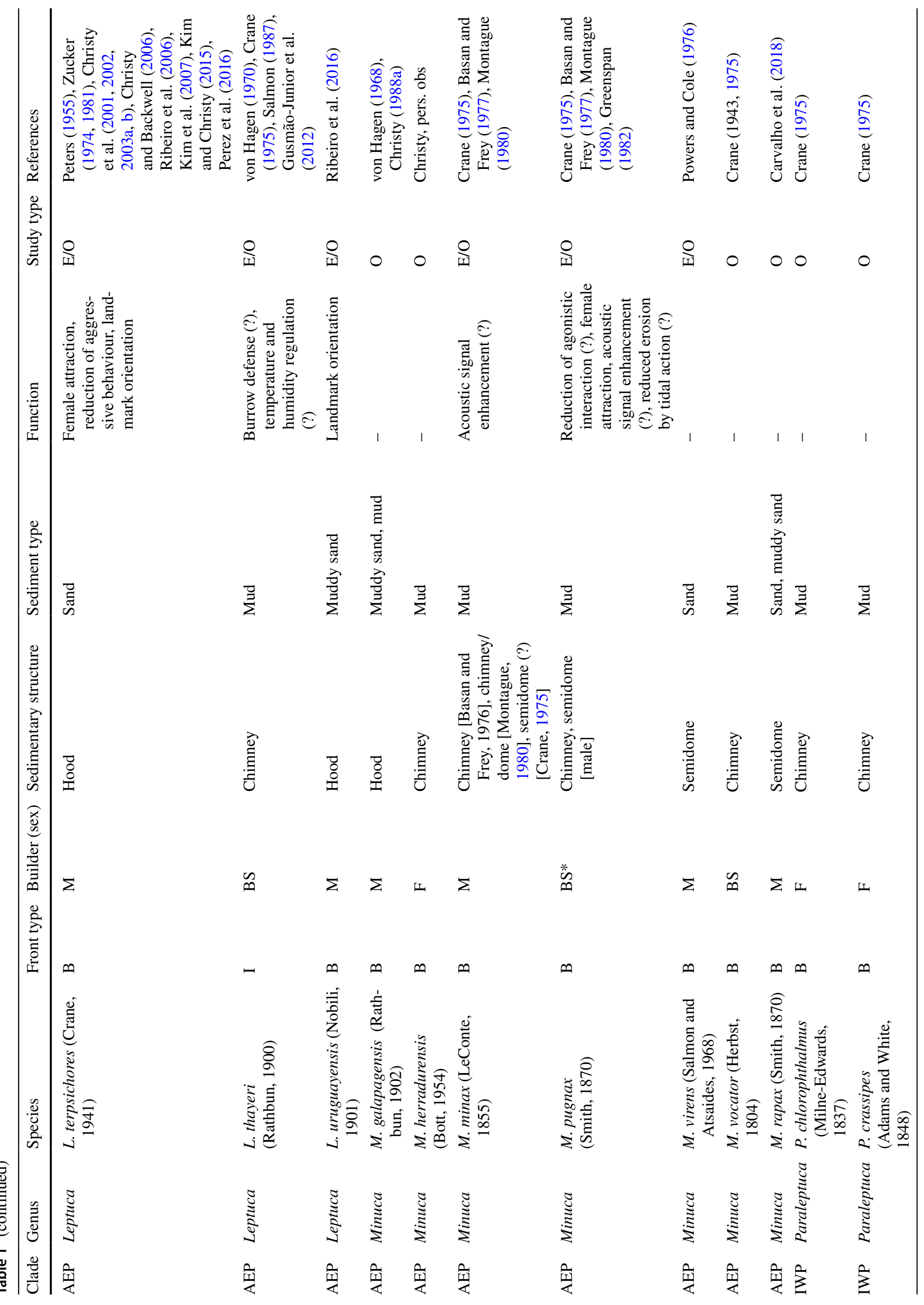




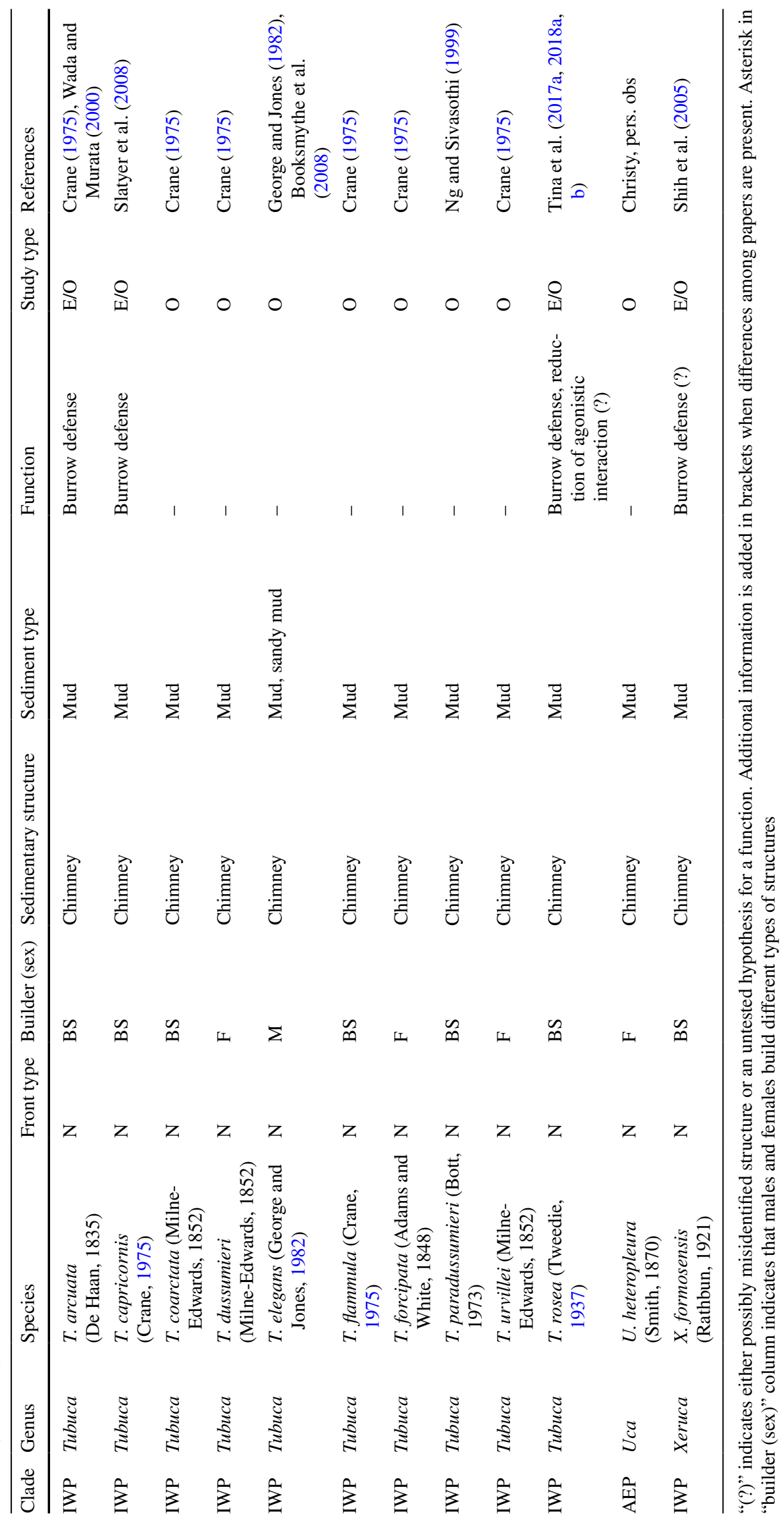


Fig. 1 The types (and subtypes) of above-ground biogenic sedimentary structures built by fiddler crabs: chimney (a), hood (b), pillar (subtype) (c), semidome (subtype) (d), mudball (e), rim (f) (drawings by FR de Grande). Drawings are not in the same scale a

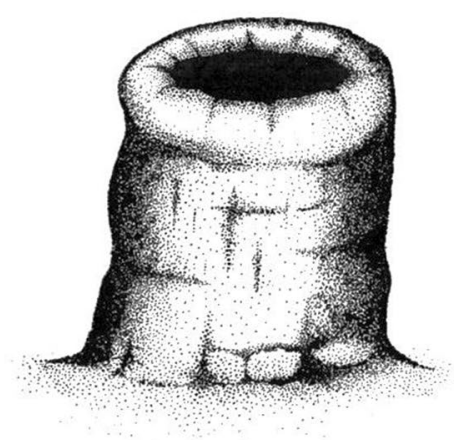

C

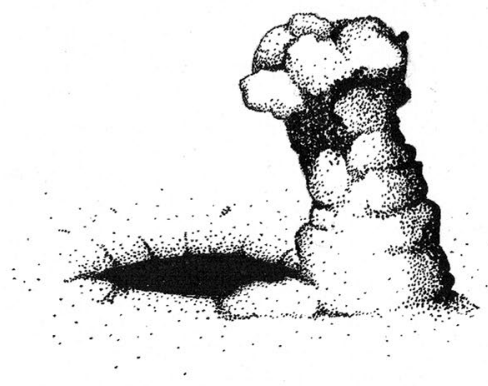

e b

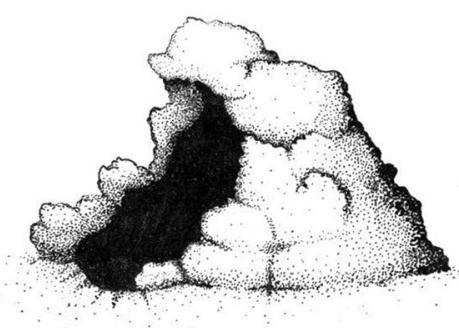

d

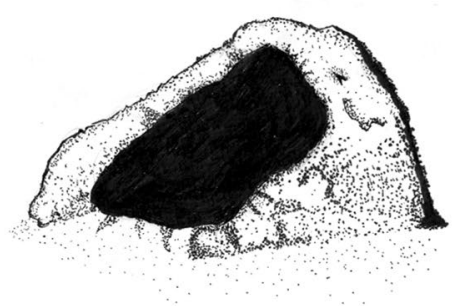

f
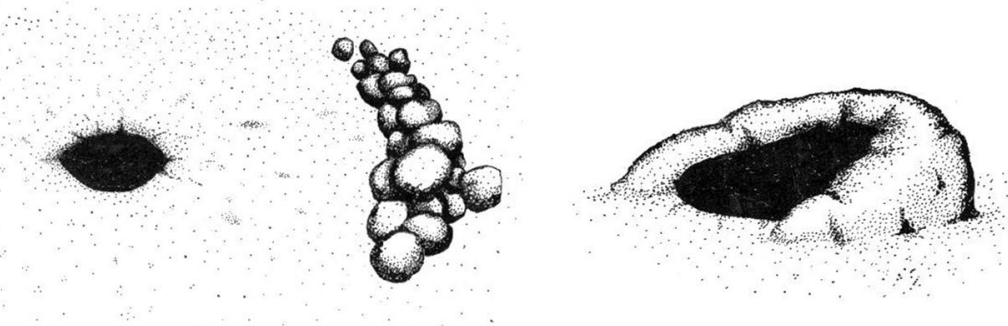

from within their burrows, while others collect with their walking legs parcels of sediment from the surface around the burrow entrance (Shih et al. 2005).

Several experimental studies have explored the functions of chimneys. Wada and Murata (2000) observed that Tubuca arcuata (De Haan, 1835) of both sexes build chimneys with higher abundance in the reproductive season of spring to summer. The authors suggested that chimneys may avoid burrow loss to an opponent based on an experiment where burrowless crabs were released near burrows with and without chimneys. Shih et al. (2005) described similar behavioral patterns in Xeruca formosensis (Rathbun, 1921), testing different hypotheses for chimney function (e.g., sexual attraction, sunshade effect). Both studies indicated that chimneys hide males from predators, while protecting females from other males.

Slatyer et al. (2008) suggested that chimney owners are "shy" crabs; crabs with chimneys generally spend more time in their burrows and less time feeding, minimizing their chances of being chased by intruders. It is still unclear whether chimneys directly or indirectly affect such behavior. The authors stated that Tubuca capricornis (Crane, 1975) chimneys hide the entrance to the burrow, making it more difficult for occasional intruders to find it, as previously mentioned for other species.

Chimney building in Leptuca thayeri (Rathbun, 1900) may also be related to burrow defense, mainly to females at late gonadal stages, thus enhancing reproductive success (Salmon 


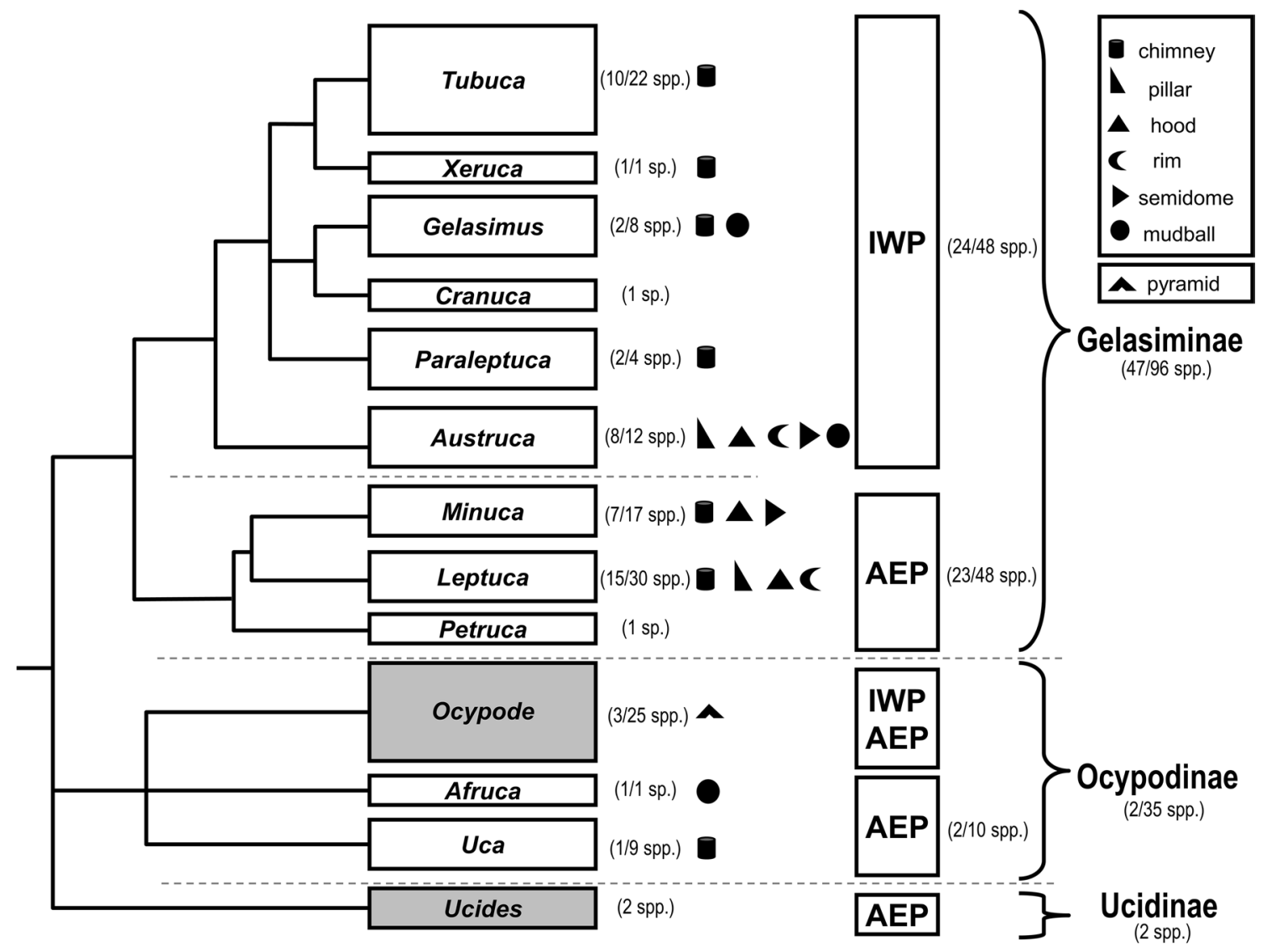

Fig. 2 Phylogenetic tree of the Ocypodidae family (Shih et al. 2016) with corresponding above-ground sedimentary structures described for each genus, clade (Atlantic-East Pacific, AEP and Indo-West Pacific, IWP) and subfamily, including the pyramid structures built

1987). Gusmão-Junior et al. (2012) stated that social context does not influence chimney construction, attributing this behavior to endogenous factors. Their main hypothesis is that chimneys may act in maintaining internal burrow conditions (Gusmão-Junior et al. 2012). As observed in Fallicambarus fodiens (Cottle, 1863) lobsters (Cambaridae) (Williams et al. 1974) and Cleistostoma dilatatum (De Haan, 1833) manicure crabs (Camptandriidae) (Kim et al. 2011), sedimentary structures (chimney and tower, respectively) may also help in the regulation of burrow evaporation and preservation of internal humidity. In this context, L. subcylindrica (Stimpson, 1859) also appear to use their above-ground sedimentary structures to maintain abiotic conditions (humidity and/or temperature), especially during dry periods (Thurman et al. 1984).

A series of studies on T. rosea (Tweedie, 1937) tested several functions for chimneys. The chimneys this species builds seem to reduce agonistic interactions and improve burrow defense against intruders (Tina et al. 2017a). Consistent with results by Slatyer et al. (2008), chimney owners spend less time feeding compared to crabs with no chimneys (Tina et al. 2018a). The energetic cost of building a by the ghost crabs Ocypode ceratophthalma (Pallas, 1772), O. kuhlii (De Haan, 1835) and O. saratan (Forskål, 1775) (Linsenmair 1967; Jones 1972)

chimney may require builders to feed faster, also as suggested by Slatyer et al. (2008). Tubuca rosea females tend to build longer and deeper burrows with higher chimneys than males's chimneys, supporting the hypotheses that chimneys may help to maintain abiotic conditions necessary for successful incubation in the burrow (Gusmão-Junior et al. 2012; Tina et al. 2018b). In sum, these experimental studies indicate that chimneys help their builders defend their burrows. Chimneys may also affect the temperature or humidity of burrows but such effects and their possible benefits to builders have yet to be demonstrated.

\section{Hood}

Hoods are morphologically varied structures typically built by males, the only fiddler crab constructions to encompass three largely different forms, including semidomes, pillars and "typical" hoods. Generally, a hood (also known as shelter or oven) consists of a cupped, roughly semi-circular mound of sediment which extends above the burrow entrance (Fig. 3b, c). While some researchers initially referred to 
hoods as shelters (Yamaguchi 1971; Zucker 1974), shelters and hoods were later recognized as being the same structure (Crane 1975; Yamaguchi 2001). Zucker (1978) explained that "shelter" implies a protective function, whereas "hood" is a functionally neutral term for these structures. Semidomes, also known as half-domes, are more massive and robust structures (Zucker 1981) (Fig. 3d). On the other hand, a pillar is a narrow, tower-like structure-sometimes conical — which is also positioned at the edge of the burrow, often with a skirt encircling the burrow opening (Fig. 3e). The terms "semidome" and "pillar" will be used throughout this text as hood subtypes, even though these constructions are also considered to be in their own category in other studies.

Typical hood builders use their chelipeds, pereiopods and the dorsal region of the carapace to manipulate sediment collected from the surface or inside their burrows into the characteristic arching shape (Christy 1982; Yamaguchi et al. 2005). As seen by Christy et al. (2001), L. terpsichores (Crane, 1941) build their hoods in one to three activity bouts, during which they do not feed. Individual males build one or two hoods per courtship cycle and from $15 \%$ to about $60 \%$ of males will build a hood on days of peak courtship. Semidome and hood construction appears to be similar (Matthews 1930; Christy et al. 2001; Chatterjee et al. 2014). Interestingly, all courting male L. pugilator (Bosc, 1801) (Christy 1982) and L. latimanus (Rathbun, 1893) (Zucker 1981) build hood-shaped structures and Kim et al. (2004) found that over $80 \%$ of Austruca lactea (De Haan, 1835) males completed their semidome structures during low tide. As for the more delicate pillars, crabs scrape surface sandy mud, carry it to the burrow with their pereiopods and pile it at the edge of the burrow's entrance with their legs and minor chelipeds (Crane 1975; Christy 1988a).

Using an experimental approach, Zucker $(1974,1981)$ provided evidence that $L$. beebei (Crane, 1941), L. latimanus and $L$. terpsichores with hoods are active primarily in the semi-circular area in front of these structures and that $L$. latimanus and L. terpsichores with hoods interact aggressively less often with their neighbors. Consequently, hoods built by $L$. terpsichores are also vital for juveniles avoiding conflict with adults (Zucker 1981). In contrast, crabs that do not build hoods defend a territory encompassing the entire area around the burrow (Zucker 1981). Christy (1988a) analyzed lengthy records of the locations and behavior of individual courting male $L$. beebei before and after they built pillars and was unable to corroborate the effects reported by Zucker (1981): pillars did not affect the distribution of male activity around the burrows nor reduce rates of aggressiveness toward males located "behind" these structures. Christy (1988a) discussed possible reasons why these two studies yielded different results.

Christy (1982) reported that burrow resident L. pugilator and M. pugnax (Smith, 1870) tend to brace themselves during fights for burrows by pressing their body against their hoods. Male $L$. pugilator usually build hoods from wet sand dug from the bottom of their burrows; as this sand dries out, salt crystals and desiccated silt act like cement increasing the rigidity of hoods and their resistance to fracture, giving residents a clear advantage over invading challengers (Christy 1982). Courting L. pugilator males always build hoods which are immediately repaired when damaged, e.g., during fights at the burrow entrance, highlighting the importance of this structure to resident builders independent of the presence of mate-searching females. In contrast, courting $L$. terpsichores and $L$. beebei build hoods and pillars, respectively, but far less often, and they usually do not rebuild these structures even when damaged 1.5-2 $\mathrm{h}$ after low tide, when most sexually receptive females would have found mates but burrow defense still remains important (Christy 1988b; Christy et al. 2001). Greenspan (1982) suggested that hoods in M. pugnax may also protect burrows from tidal erosion. Yet, at least for the hooded "breeding burrows" of $L$. pugilator found in the supra-tidal zone, tidal erosion is not a problem (Christy 1982).

Hoods also attract females and hood building is sexually selected by female choice (Christy et al. 2002). Courting male $L$. terpsichores build hoods at the time of the monthly and daily tidal cycles when most females seek mates (Christy et al. 2001). Small males tend to build relatively high structures, increasing their conspicuousness (Christy et al. 2001). Christy et al. (2002) experimentally showed that L. terpsichores females are differentially attracted to courting males that build hoods (approach rates: with hood $=0.84$; without hood $=0.66 ; n=354$ approaches) even when replicas of hoods are added to the burrows of males that do not build hoods, suggesting that hoods contribute directly to male attractiveness. Most convincing were experiments in which hood replicas are positioned about $3 \mathrm{~cm}$ away from the entrances of males's burrows; females orient to these structures rather than to the courting male about $40 \%$ of the time when the male does not directly lead the female to the entrance to his burrow. In contrast, Perez et al. (2016) did not find a female preference for $L$. terpsichores males with hoods, possibly due to the much smaller sample size in that study ( $n=28$ approaches). Similarly, de O. Rodrigues et al. (2016) also showed that hoods built by male L. leptodactyla attract females.

Male crabs also orient to their own hoods. In field experiments using displaced hoods, some males that move far from their burrows to intercept passing females lead the females not to their burrow entrance but to the nearby hood replica (Christy et al. 2002). This simple observation prompted a new line of study indicating that hood building is under sexual selection by indirect male-male competition to maintain burrow ownership as well as natural selection for the ability to visually relocate a burrow in a quick manner (Ribeiro 


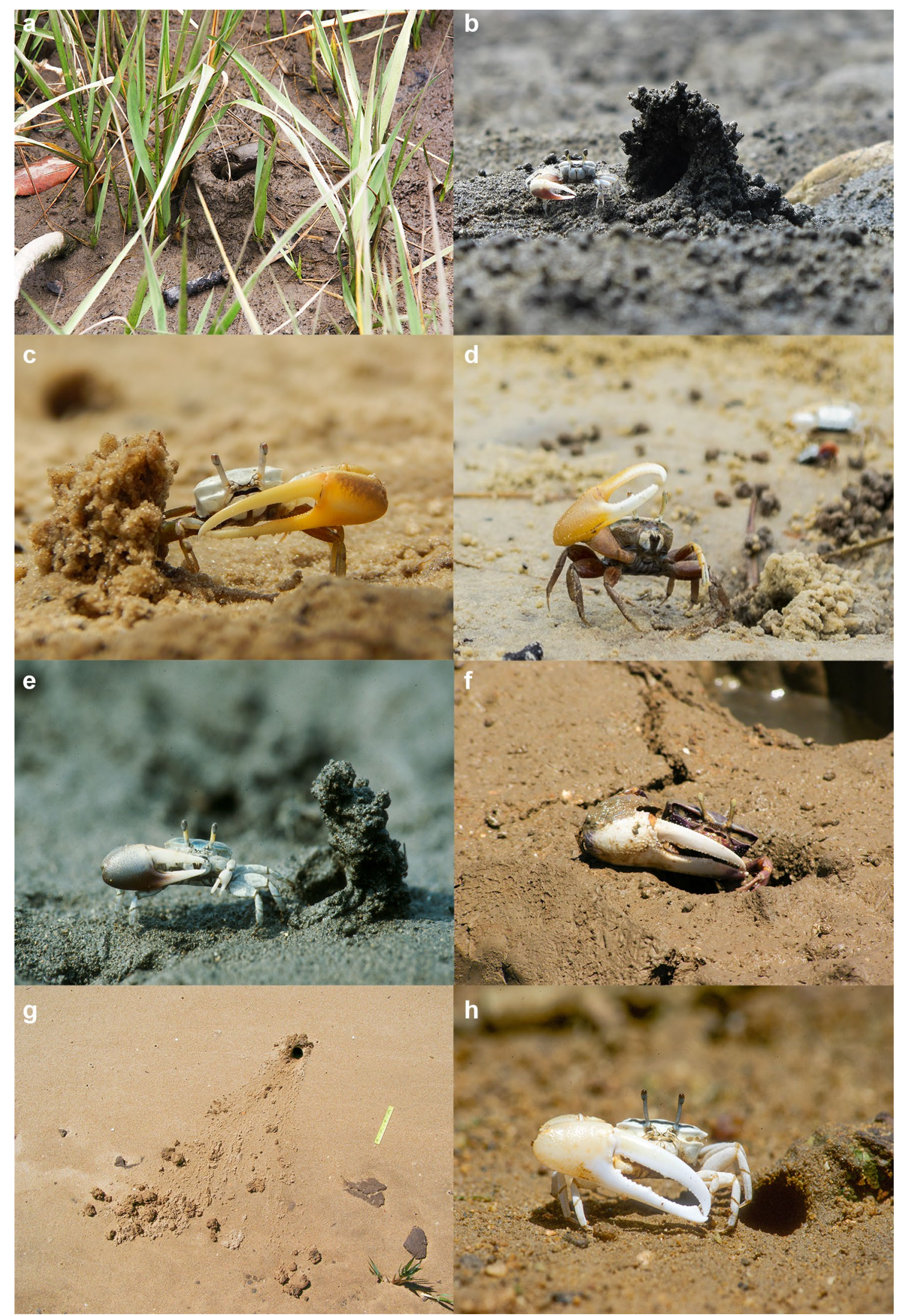


4Fig. 3 Examples of fiddler crabs that build above-ground sedimentary structures. a Ovigerous female of Leptuca thayeri on a chimney, Bertioga, Brazil (photograph by J Pardo). b Male Leptuca terpsichores with a hood, Achotines, Panamá (photograph by J Christy). c Male Leptuca leptodactyla with a hood, Peruíbe, Brazil (photograph by R de Carvalho). d Male Minuca rapax waving near a semidome, Peruíbe, Brasil (photograph by J Pardo). e Male Leptuca beebei with a pillar, Rodman, Panamá (photograph by J Christy). f Male Afruca tangeri, Nueva Umbria, Spain (photograph by M Hyzny). g Mudballs arranged by male Afruca tangeri (photograph by M Hyzny). $\mathbf{h}$ Male Austruca perplexa with a rim, Okinawa, Japan (photograph by J Christy)

et al. 2006). Hoods not only assist males in orienting back to their burrow, but also enable males to move more freely when courting, suggesting they are visual beacons marking a male's home burrow (Kim and Christy 2015). Heatwole et al. (2018) found, however, that males with hoods are no more likely to reach passing females and do not move greater distances from their burrows compared to males without hoods. Since males of this species typically move no more than $17 \mathrm{~cm}$ away from their burrows to attract females, hoods may not be beneficial as home beacons during most courtship interactions (Heatwole et al. 2018).

Hood building by male L. terpsichores appears to be selected by female choice, male-male competition for resource (burrow) holding, and predation on both sexes (Ribeiro et al. 2006). Sexual signals that are favored by both modes of sexual selection, typically operating in sequence, are not unusual (Hunt et al. 2009). It has been argued that females should prefer male traits that have been tested in combat because they will reliably advertise male condition, which might benefit females directly or via indirect genetic benefits to the offspring (Berglund et al. 1996). Although structure building (Backwell et al. 1995; Matsumasa et al. 2013) and investment in other courtship behavior (Kim et al. 2010) are condition dependent, hoods may attract both sexes and facilitate burrow location because they elicit landmark orientation. This "sensory trap" hypothesis (Christy 1995) as it pertains to female preference has received considerable experimental support (summarized by Christy 2007), including demonstration that the preference for pillars built by $L$. beebei (Kim et al. 2006) and the preference for hoods built by L. terpsichores (Kim et al. 2007) increase with the perceived risk of predation in females. Although females that choose males with structures may enjoy reproductive benefits by mating with males in good condition, such benefits cannot explain why males, females not seeking mates and females of species that do not build structures are attracted to them (Christy 2007).

The effects and functions of the semidomes built by $A$. lactea have also been well-described. Studies of this species in Japan use the word "hood" (e.g., Yamaguchi et al. 2005; Muramatsu 2010a, b); while Korean studies prefer "semidome" (e.g., Kim et al. 2004; Zhu et al. 2012). Field experiments showed that semidomes are sexual signals, reduce aggressive interactions and are landmarks for male orientation (see references in Table 1). Kim and Choe (2003) also showed that semidome building in A. lactea is related to the semilunar cycle of tidal inundation, which in turn affects food abundance: males that are given supplemental food build more semidomes. The frequency of semidome building, however, seems to be independent of food abundance, being instead dependent on environmental factors such as temperature (Takeshita et al. 2018).

Zhu et al. (2012) explored the effects of semidome size on female orientation. Females prefer courting males with normal-sized semidomes over those with half-sized or no semidome when seeking mates. When startled by a mock predator, females orient preferentially to empty burrows with full-sized semidomes over those with half-size or no semidome both during and outside the breeding period. When no predator is present, females differentially orient to burrows with structures (equally to full- and half-sized structures) over those without structures during the breeding period but not during the nonbreeding period. Hence, both level of risk and the reproductive state of the female may potentiate her orientation response to structures. Under reduced predation risk, female preference for larger structures appears to be contingent upon other stimuli from the courting male. Landmark orientation in service of mate choice (the response to the mimic in a sensory trap) and in service of risk reduction (the response selected by the model) may be flexibly linked to the benefit to females in both contexts. A recent study by Kim et al. (2017) further supports such flexibility; female A. lactea preferentially approach sedimentary structures (in test arenas without males) only during reproductive periods and males do not differentially orient to structures. Kim et al. (2017) suggested a divergent evolutionary path in the group for this behavior, where orientation to hoods by females during courtship and to vertical objects for risk reduction evolved independently. Interestingly, the closely related species A. mjoebergi rarely builds semidomes, due to loss of attractive function that is possibly mediated by predation and environmental changes (Bourdiol et al. 2018).

Pillar building is a condition-dependent behavior, carried out by six species (see Table 1); male L. beebei, for example, build more pillars when given supplemental food (Backwell et al. 1995) and pillar builders allocate more energy and time to claw waving and less to feeding compared to non-builders. Females of this species approach structures not only for mating but also for protection (Christy 1988b; Christy et al. 2003b), which is consistent with the sensory trap hypothesis (Christy 1995; Kim et al. 2009). Although males with pillars attract more females to their burrows, once attracted to a male and burrow, females are equally likely to stay and mate whether or not the male has a pillar (Christy 1987). Pillars, thus, signal both male condition and the location of male 
burrows to breeding females (Christy 1988a, b; Backwell et al. 1995; Matsumasa et al. 2013). Under high predation risk, male $L$. beebei tend to build fewer pillars, either because males spend more time sheltering in their burrows or because fewer females wander to find mates, reducing the benefits of having a pillar (Koga et al. 1998; deRivera et al. 2003) despite the low energetic cost to build these structures (Matsumasa et al. 2013). Finally, pillars in other species are often regarded as "poorly-formed hoods" (Crane 1975).

Hoods in general, thus, appear to attract females, orient male movement and reduce antagonistic behavior and reduce predation risk for both sexes. Semidomes, as well as the possible functions mentioned above, may further aid in burrow defense. Pillars, on the other hand, seem to be exclusively related to orientation and mate attraction. Although the sensory trap hypothesis has helped explain why both sexes orient to sedimentary structures, recent studies suggest that orientation for risk reduction and in service of mate choice can be uncoupled and evolve independently. The sensory trap hypothesis should not be uncritically used to explain how structure building benefits males in all species.

\section{Mudball}

Mudballs are large, roughly spherical pellets of substrate that crabs remove from the burrow during excavation and deposit on the surface around the burrow entrance (Fig. 3f, g). All fiddler crabs that dig burrows make similar balls of sand or mud during burrow construction. Mudballing, when thought to have a social function, is the term used for this behavior in both male and female Afruca annulipes, A. bengali (Crane, 1975), A. tangeri (Eydoux, 1835), and Gelasimus tetragonon (Herbst, 1790). Mudballs and their deposition differ between sexes. Oliveira et al. (1998) stated that muballs produced by male A. tangeri are larger than females's, although this could be related to the larger volume of male burrows (Latruffe et al. 1999). Chatterjee et al. (2014) showed similar results in A. bengali mudballs and Tina et al. (2017b) observed a positive correlation between $A$. annulipes carapace width and number of mudballs. Also, females of $A$. tangeri and A. annulipes tend to deposit theirs in a mound near the burrow opening, while males usually position their mudballs far from the burrow entrance (Oliveira et al. 1998; Burford et al. 2001b; Tina et al. 2017b). Interestingly, Burford et al. (2001c) observed that some females exhibit a male-like mudballing behavior, with similar structural arrangement of mudballs; the authors suggested that their masculinization may either be a consequence of parasite infestation or constitute a behavior to avoid harassment. Mudball function remains unclear in A. bengali and G. tetragonon (Weis and Weis 2004; Chatterjee et al. 2014).

Mudballing behavior in A. tangeri was first described in the early 1960s (Günther 1963). In previous studies, mudballs were described as a consequential product of excavation (Crane 1975). Behavioral studies with this species, however, showed that both sexes spend more than two hours on mudball maintenance (Burford et al. 2001c), and also suggested that their function is to define territorial boundaries and prevent invasion and/or conflict with other individuals (Oliveira et al. 1998; Burford et al. 2000, 2001a). Sharing a similar purpose, structures built by the genus Ilyoplax (Stimpson, 1858), which are made from surface sediments, have also been extensively studied. Barricades and/or fences near burrows are built to deter the approach of potential competitors and maintain territory (Wada 1984, 1994; Wada et al. 1998; Christy and Wada 2015).

Oliveira et al. (1998) proposed that A. tangeri mudballs attract females, with males producing larger and more numerous mudballs than females. The number of mudballs may be also related to the degree to which the burrow collapsed during the previous high tide. Latruffe et al. (1999) claimed that females may relate male structures and mudball distance to the depth of the male's burrow and, consequently, to burrow quality for breeding (Latruffe et al. 1999), but subsequent studies found little support for this function (Burford et al. 2001a). Males invest more in the claw waving display to attract females during the courtship phase than in mudball maintenance (Burford et al. 2001a).

Mudballs may also increase male conspicuousness when exposed to different backgrounds, although Cummings et al. (2008) stated that these hypotheses required more studies to determine that specific role. At present, the likely function of mudballs lies in territorial behavior.

\section{Rim}

Rims or lips are circular, elevated rings of sediment built around the edge of the burrow opening (Fig. 3h). Male crabs usually mold rims from sand with their major claw and ambulatory legs (Salmon et al. 1978; deRivera 2003; Christy 2007). No experiments to determine the functions of rims have been done. Salmon et al. (1978) noticed that intruder male $L$. panacea often destroy the owner's burrow entrance. Additionally, Christy (2007) suggested that A. perplexa rims may make burrow openings more visible from a distance and help both males and approaching females locate the burrow.

\section{Results and discussion}

\section{Are fiddler crab above-ground sedimentary structures associated with general attributes?}

The first two factorial axes of the MCA explained $28.89 \%$ of the variance (F1: 18.30\%, F2: 11.59\%, Fig. 4) and the complementary Cramer's V test showed that types (subtypes) of 


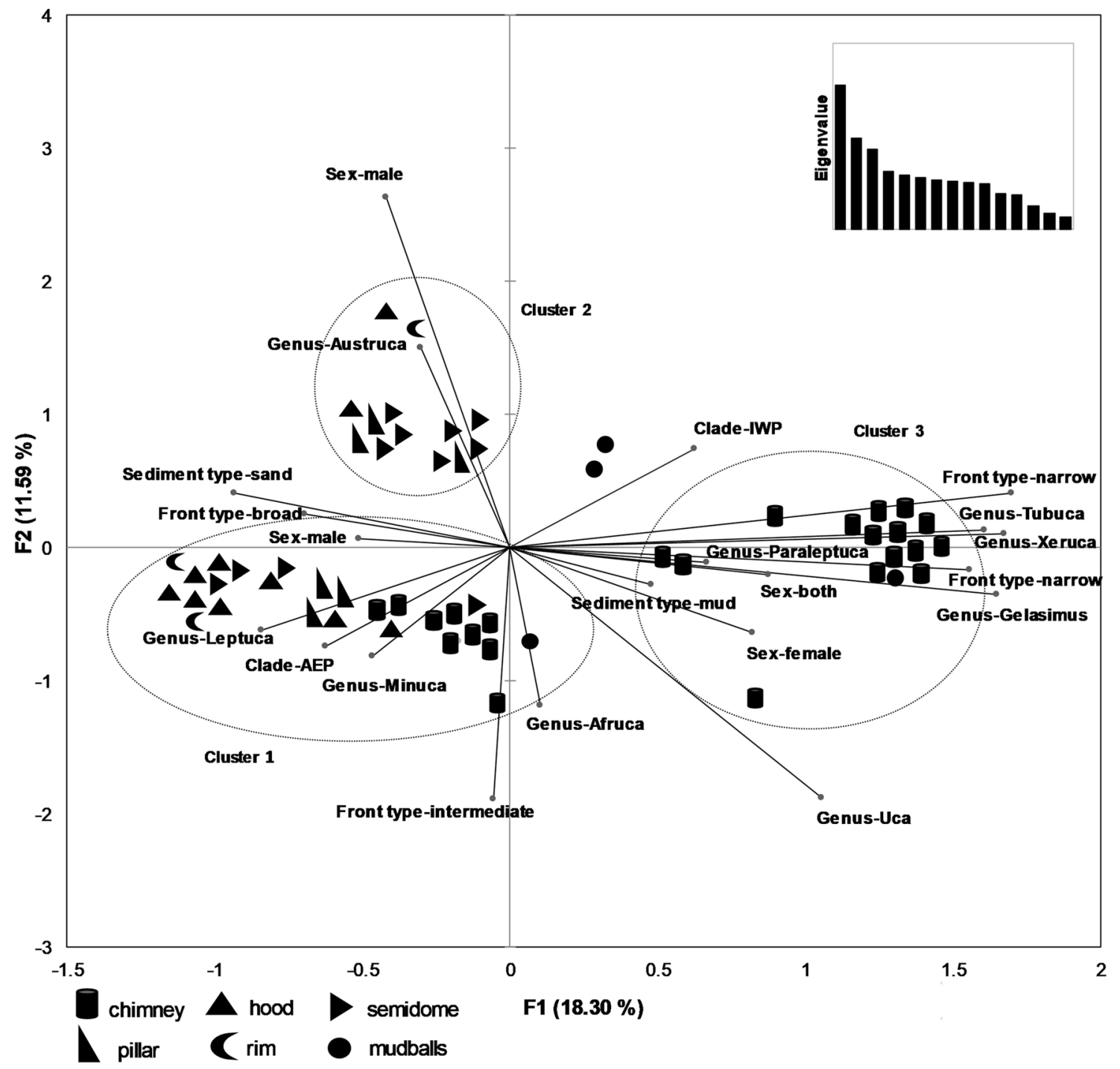

Fig. 4 Multiple correspondence analysis. Plots of the following variables on the first two dimensions (F1 and F2) with the eigenvalue: clade (AEP: Atlantic-East Pacific, IWP: Indo-West Pacific), genus (Austruca, Afruca, Gelasimus, Leptuca, Minuca, Paraleptuca,
Tubuca, Uca, Хеruca), front type (broad, narrow, intermediate), sex (male, female, both sexes), structure (chimney, hood, pillar, semidome, mudball, rim), type of sediment used to build structures [mud (including sandy mud), sand (including muddy sand), both types]

Table 2 Chi-Square and Cramer's $V$ results comparing sedimentary structures with clade, front, genus, sex and sediment data

\begin{tabular}{lllllll}
\hline & & \multicolumn{2}{l}{ Chi-square } & & \multicolumn{2}{c}{ Cramer's $V$} \\
\cline { 6 - 7 } Variables & & Value & $d f$ & $p$ & & Value \\
\hline Sedimentary & Clade & 4.831 & 5 & 10 & 0.437 & 0.289 \\
structure & Front & 26.352 & 40 & 10 & $\mathbf{0 . 0 0 3}$ & 0.443 \\
& Genus & 59.321 & 10 & $\mathbf{0 . 0 2 5}$ & 0.446 \\
& Sex & 37.112 & $\mathbf{0 . 0 0 1}$ & 0.533 \\
& Sediment & 33.134 & $\mathbf{0 . 0 0 1}$ & 0.515 \\
\hline
\end{tabular}

Statistically significant $p$-values are in bold

sedimentary structures are strongly associated with front, genus, sex and sediment, but not clade (Tables 2 and 3).
A variety of types (subtypes) of structures are associated in Cluster 1, being explained by the AEP clade and the 
Table 3 Principal coordinates obtained in the MCA for the first two axes (F1 and F2)

\begin{tabular}{lll}
\hline Variable & F1 & F2 \\
\hline Clade-AEP & -0.626 & -0.741 \\
Clade-IWP & 0.626 & 0.741 \\
Genus-Afruca & 0.101 & -1.182 \\
Genus-Austruca & -0.302 & 1.499 \\
Genus-Gelasimus & 1.650 & -0.349 \\
Genus-Leptuca & -0.841 & -0.615 \\
Genus-Minuca & -0.464 & -0.817 \\
Genus-Paraleptuca & 0.669 & -0.107 \\
Genus-Tubuca & 1.607 & 0.131 \\
Genus-Uca & 1.057 & -1.876 \\
Genus-Xeruca & 1.676 & 0.103 \\
Front-Broad & -0.513 & 0.071 \\
Front-Intermediate & -0.055 & -1.889 \\
Front-Narrow & 1.559 & -0.165 \\
Sex-Both sexes & 0.874 & -0.201 \\
Sex-Female & 0.821 & -0.640 \\
Sex-Male & -0.695 & 0.248 \\
Sediment-Mud & 0.477 & -0.276 \\
Sediment-Sand & -0.932 & 0.413 \\
Explained variance $(\%)$ & 18.30 & 11.59 \\
\hline
\end{tabular}

genera Leptuca and Minuca. Otherwise, with few exceptions, builders of the IWP clade form two groups: hoodbuilders of the genus Austruca (Cluster 2) and chimneybuilders of Gelasimus, Tubuca and Xeruca (Cluster 3). As mentioned, clade was the only attribute that did not correlate with structure type, where all shapes are present at least once in both clades (Fig. 2). Clades (AEP and IWP) are expressively divergent and paraphyletic (Shih et al. 2016) indicating a non-phylogenetic relationship in the evolutionary history of fiddler crab structure types. However, fiddler crab genera correlated with structure type, which suggests that structures readily diversified due perhaps to social and environmental factors. From these novel inferences, further studies could explore intra-generic relationships using phylogeny-based comparative approaches.

There is an apparent relationship between above-ground sedimentary structures and sediment type. Upon close inspection of the summarized data, chimneys seem to be more common in muddy/muddy sand habitats, pillars are more common in sandy mud, hoods/semidomes and rims are usually built in sand, and mudballs are a by-product of burrow construction in muddy sediments (see references in Table 1). These associations indicate that the cohesiveness of sandy mud may facilitate construction of delicate structures, such as pillars, which probably cannot be built of more friable sand (Christy 1988b). Field experiments in which replicas of hoods were placed on the burrows of courting male $L$. beebei and replicas of pillars were placed on the burrows of courting male $L$. terpsichores showed that hoods, the larger of the two structures (structure height was equal), are most attractive to females of both species (Christy et al. 2003a). However, L. beebei males with hoods do not mate at a greater rate than those with pillars because hoods may visually shield some passing females, affecting male-female encounter rates. Hence, there was no evidence that signal competition currently selects for hood building by pillar building $L$. beebei. Experimental studies manipulating sediment type and properties are needed to test these ideas. Sediment saturation also influences structure shape: Kim et al. (2004) hypothesized that semidome building is usually limited by water content of the soil, showing that A. lactea males are stimulated to build semidomes when the surrounding area is not dry and hard. This may explain why hood building typically occurs before low tide in $L$. terpsichores (Christy et al. 2001) and why L. pugilator use moist sand from the bottom of their burrows to build hoods (Christy 1982). Additionally, Mokhlesi et al. (2011) observed that the muddy areas inhabited by A. annulipes, a multi-structure builder, allow building behavior; whereas the sandy and drier sediments in which A. sindensis (Alcock 1900) burrows limit structure building. These effects of soil moisture on construction behavior have been observed in other groups; for example, Grow (1981) found that chimney building by the crayfish Cambarus diogenes diogenes (Girard, 1852) depends on the percentage of soil moisture. Experimental studies on the effects of sediment type and moisture content on fiddler crab structure building have yet to be conducted.

The majority of chimney builders gathered in Cluster 3 seems strongly associated with the narrow-front characteristic and the genera Gelasimus, Tubuca and Xeruca. Both sexes build chimneys, with these structures serving as barriers against potential invaders (Slatyer et al. 2008; Wada and Murata 2000; Gusmão-Junior et al. 2012; Tina et al. 2017a). Narrow-front species tend to mate on the surface close to burrows built by females, and these females are typically more aggressive toward intruders than are females of broadfront species (Christy and Salmon 1991). As females tend to build more robust and taller structures than males, chimneys are likely to play an important role in female incubation behavior in these species.

\section{Toward a common nomenclature}

Authors have used different terms for the same structures built by fiddler crabs. Peters (1955) and Montague (1980) attributed chimney building ("towers") to M. pugnax; while, both Crane (1975) and Greenspan (1982) showed that this species builds hoods. Crane (1975, page 284) observed chimney building behavior in one population of L. stenodactylus in the Panama Canal Zone, but Müller (1989) called 
Table 4 Simplified definitions of the six types and subtypes of sedimentary structures built by fiddler crabs

\begin{tabular}{ll}
\hline Type (subtype) & Definition \\
\hline Chimney & Tower-shaped structure whose walls completely encircle the burrow entrance \\
Hood & Cupped, semi-circular and rounded projection above the burrow entrance \\
Semidome & Massive and robust semi-hooded structure at the burrow entrance \\
Pillar & Narrow, column-like structure at the edge of the burrow entrance \\
Mudball & Large, roughly spherical pellets of substrate deliberately arranged around the \\
burrow entrance & Circular, elevated ring of sediment around the edge of the burrow entrance \\
\hline
\end{tabular}

such structures "pillars or columns". Leptuca stenodactylus populations, however, have been extensively observed in Panama with no indications of such structure building behavior (JH Christy, pers. obs.). This species often overlaps with the hood builder $L$. terpsichores, which may have caused misinterpretations. Some species were nevertheless observed building more than one type of structure, highlighting the importance of detailed and concise ethological descriptions.

The lack of simplified definitions for fiddler crab structures may explain some inconsistencies in the current literature. Pope and Haney (2008) described in detail both $L$. musica (Rathbun, 1914) and L. latimanus hood structures showing their differences and context-dependent variations in shape. Upon close inspection of the authors's figures and description of L. latimanus structures, we believe that $L$. latimanus hoods could be instead semidomes; the same applying to Zucker (1981) when using hoods instead of semidomes. Similarly, Mokhlesi et al. (2011) described four distinct types and subtypes of structures built by $A$. annulipes (Milne-Edwards, 1837), differentiating between hoods, pillars, mudballs and semidomes; the semidome structures shown in their figures appear to be yet another type of above-ground sedimentary structure. This species, thus, builds four structures in addition to this novel structure. Moreover, in their review of African fiddler crabs, Peer et al. (2015) ascribed dome building to G. hesperiae (Crane, 1975) [previously $U$. (T.) vocans hesperiae] but we have been unable to find this passage in Crane's work.

Above-ground sedimentary structures seem to have a crucial role for juvenile and smaller crabs. Benefits such as burrow protection may lead them to build higher or even a larger number of structures than adults in some species (Günther 1963; Zucker 1974, 1981; Wada and Murata 2000). There is, however, an additional behavior observed by Günther (1963) where smaller-sized A. tangeri rarely build "turret buildings". This unusual and undescribed type of structure was mentioned by Crane (1975) and more recently attributed to C. inversa (Atkinson and Eastman 2015). Günther (1963) distinguished that structure from the "walled holes" (chimneys) constructed by M. vocator (Crane, 1943). Until now, no other studies have provided detailed descriptions of the "turret" structures built by fiddler crabs. Future ethological studies could reveal if turrets are just a by-product of excavated pellets or an actual functional structure.

\section{Conclusions and future directions}

Fiddler crabs and their above-ground sedimentary structures have been used as a model in ecological and ethological studies. Researchers have proposed several hypotheses concerning structure function for a few species, yet most remain untested experimentally. Explanations for structure function that have been experimentally tested include courtship signaling and biasing of activity space, reduction of territorial overlap, visual orientation, refuge from predation, intruder exclusion and reduction of aggression between neighbors. Future studies should evaluate structure function using equivalent experimental designs on species that build similar constructions. This, along with the use of simplified terms for these structures, would facilitate comparisons between groups, especially when referring to hood subtypes, i.e., pillars and semidomes (Table 4).

We envisage an integration between field observations and experiments in which structures are altered or removed to determine their effects on social interactions and burrow microclimate, with varying sediment characteristics. Apart from their functions in relation to fiddler crabs, we also lack an understanding of how these structures may affect sediment biogeochemistry and habitat for associated groups, especially meiofauna and microbial communities (Bell et al. 1978; Kristensen 2008; González-Ortiz et al. 2014; Nobbs and Blamires 2015; Citadin et al. 2016). A combined approach should give us a better understanding of the relationship between architecture, function and ecological effects of these biogenic constructions.

Acknowledgements Open Access funding provided by the University of Agder. We thank PM Whelan and AS Augusto for the early discussions and suggestions concerning this manuscript, HT Shih for allowing the use of his published image, FR de Grande for the drawings and $\mathrm{R}$ de Carvalho and M Hyzny for providing their photographs. We also thank Chief Editor K Nakata and the anonymous reviewers for their valuable comments on the manuscript. 
Author contributions JCFP and TMC envisioned the article, JCFP and GS-S drafted the manuscript and performed the literature search and data analysis, JCFP, GS-S, JHC and TMC contributed to the writing and critically revised the work.

Funding JCF Pardo was supported by the Coordenação de Aperfeiçoamento de Pessoal de Nível Superior (CAPES) (88888.013890/2013-00) and the Fundação de Amparo à Pesquisa do Estado de São Paulo (FAPESP) (2011/23611-0). TM Costa was supported by the Conselho Nacional de Desenvolvimento Científico e Tecnológico (CNPq) (\#303400/2012-9) and FAPESP (2010/09763-9).

\section{Compliance with ethical standards}

Conflict of interest The authors declare that they have no conflict of interest.

Open Access This article is licensed under a Creative Commons Attribution 4.0 International License, which permits use, sharing, adaptation, distribution and reproduction in any medium or format, as long as you give appropriate credit to the original author(s) and the source, provide a link to the Creative Commons licence, and indicate if changes were made. The images or other third party material in this article are included in the article's Creative Commons licence, unless indicated otherwise in a credit line to the material. If material is not included in the article's Creative Commons licence and your intended use is not permitted by statutory regulation or exceeds the permitted use, you will need to obtain permission directly from the copyright holder. To view a copy of this licence, visit http://creativecommons.org/licenses/by/4.0/.

\section{References}

Atkinson RJA, Eastman LB (2015) Burrow dwelling in Crustacea. In: Thiel M, Watling L (eds) The natural history of the Crustacea lifestyles and feeding biology, vol 2. Oxford University Press, New York, pp 100-140

Backwell PRY, Jennions MD, Christy JH, Schober U (1995) Pillar building in the fiddler crab Uca beebei: evidence for a conditiondependent ornament. Behav Ecol Sociobiol 36:185-192

Bailey NW (2012) Evolutionary models of extended phenotype. Trends Ecol Evol 27:561-569

Basan PB, Frey RW (1977) Actual-palaeontology and neo-ichnology of salt marshes near Sapelo Island, Georgia. Trace Fossils 2:41-70

Bell SS, Watzin MC, Coull BC (1978) Biogenic structure and its effect on the spatial heterogeneity of meiofauna in a salt marsh. J Exp Mar Biol Ecol 35:99-107

Berglund A, Bisazza A, Pilastro A (1996) Armaments and ornaments: an evolutionary explanation of traits of dual utility. Biol L Linn Soc 58:385-399

Booksmythe I, Detto T, Backwell PRY (2008) A field guide to the fiddler crabs of East Point Reserve, Darwin, Northern Territory. North Territ Nat 20:26-33

Bourdiol J, Chou CC, Perez DM, Backwell PRY (2018) Investigating the role of a mud structure in a fiddler crab: do semidomes have a reproductive function? Behav Ecol Sociobiol 72:141

Burford FR, McGregor PK, Oliveira RF (2000) The sequence of mudball placement by male fiddler crabs, Uca tangeri. Etología 8:53-55

Burford FR, McGregor PK, Oliveira RF (2001a) Mudballing revisited: further investigations into the construction behaviour of male Uca tangeri. Behaviour 138:221-234
Burford FR, McGregor PK, Oliveira RF (2001b) Intersexual differences in the mudballs of Uca annulipes (Decapoda: Ocypodidae). J Mar Biol Assoc UK 81:353-354

Burford FR, McGregor PK, Oliveira RF (2001c) Male-like mudballing behavior of some female fiddler crabs (Uca tangeri). J Ethol 19:97-103

Carvalho RD, Pardo JCF, Costa TM (2018) Construction and structure of the semidomes of the fiddler crab Minuca rapax (Brachyura: Ocypodidae) in southern Brazil. J Crust Biol 38:241-244

Chatterjee S, Mazumdar D, Chakraborty SK (2014) Ecological role of fiddler crabs (Uca spp.) through bioturbatory activities in the coastal belt of East Midnapore, West Bengal, India. J Mar Biol Assoc India 56:2

Christy JH (1982) Burrow structure and the use in the sand fiddler crab, Uca pugilator (Bosc). Anim Behav 30:687-694

Christy JH (1987) Female choice and the breeding behavior of the fiddler crab Uca beebei. J Crust Biol 7:624-635

Christy JH (1988a) Pillar function in the fiddler crab Uca beebei (I): effects on male spacing and aggression. Ethology 78:53-71

Christy JH (1988b) Pillar function in the fiddler crab Uca beebei (II): competitive courtship signaling. Ethology 78:113-128

Christy JH (1995) Mimicry, mate choice and the sensory trap hypothesis. Am Nat 146:171-181

Christy JH (2007) Predation and the reproductive behavior of fiddler crabs (genus Uca). In: Duffy JE, Thiel M (eds) Evolutionary ecology of social and sexual systems, crustaceans as model organisms. Oxford University Press, Oxford, pp 211-231

Christy JH, Backwell PRY (2006) No preference for exaggerated courtship signals in a sensory trap. Anim Behav 71:1239-1246

Christy JH, Salmon M (1991) Comparative studies of reproductive behavior in mantis shrimps and fiddler crabs. Am Zool 31:329-337

Christy JH, Schober UM (1994) A test for resource-defence mating in the fiddler crab Uca beebei. Anim Behav 48:795-802

Christy JH, Wada K (2015) Social ethology in Brachyura. In: Castro P, Davie PJF, Guinot D, Schram FR, von Vaupel Klein JC (eds) Treatise on zoology—anatomy, taxonomy, biology: the crustacea part C, vol 9. Brill, Leiden, pp 417-468

Christy JH, Backwell PRY, Goshima S (2001) The design and production of a sexual signal: hoods and hood building by male fiddler crabs Uca musica. Behaviour 138:1065-1083

Christy JH, Backwell PRY, Goshima S, Kreuter T (2002) Sexual selection for structure building by courting male fiddler crabs: an experimental study of behavioral mechanisms. Behav Ecol $13: 366-374$

Christy JH, Backwell PRY, Schober U (2003a) Interspecific attractiveness of structures built by courting male fiddler crabs: experimental evidence of a sensory trap. Behav Ecol Sociobiol 53:84-91

Christy JH, Baum JK, Backwell PRY (2003b) Attractiveness of sand hoods built by courting male fiddler crabs, Uca musica: test of a sensory trap hypothesis. Anim Behav 66:89-94

Citadin M, Costa TM, Netto SA (2016) The response of meiofauna and microphytobenthos to engineering effects of fiddler crabs on a subtropical intertidal sandflat. Austral Ecol 41:572-579

Crane J (1975) Fiddler crabs of the world (Ocypodidae: genus Uca). Princeton University Press, Princeton

Cummings ME, Jordão JM, Cronin TW, Oliveira RF (2008) Visual ecology of the fiddler crab, Uca tangeri: effects of sex, viewer and background on conspicuousness. Anim Behav 75:175-188

Dawkins R (1982) The extended phenotype. Oxford University Press, Oxford

De C (2000) Neoichnological activities of endobenthic invertebrates in downdrift coastal Ganges delta complex, India: their significance in trace fossil interpretations and paleoshoreline reconstructions. Ichnos 7:89-113 
de O. Rodrigues R, Costa TM, Barreto RE (2016) Burrow ornamentation in the fiddler crab (Uca leptodactyla): female mate choice and male-male competition. Mar Freshw Behav Physiol 49:317-325

deRivera CE (2003) Behavioral and ecological correlates of female mate searching in the fiddler crab Uca crenulata. Ethol Ecol Evol 15:235-249

deRivera CE, Backwell PRY, Christy JH, Vehrencamp SL (2003) Density affects female and male mate searching in the fiddler crab, Uca beebei. Behav Ecol Sociobiol 53:72-83

Frey RW (1973) Concepts in the study of biogenic sedimentary structures. J Sediment Res 43:6-19

George RW, Jones DS (1982) A revision of the fiddler crabs of Australia (Ocypodinae: Uca). Rec Western Aust Mus 14:5-99

González-Ortiz V, Alcazar P, Vergara JJ, Pérez-Lloréns JL, Brun FG (2014) Effects of two antagonistic ecosystem engineers on infaunal diversity. Estuar Coast Shelf Sci 39:20-26

Greenacre M, Blasius J (2006) Multiple correspondence analysis and related methods. Chapman and Hall/CRC, London

Greenspan BN (1982) Semi-monthly reproductive cycles in male and female fiddler crabs, Uca pugnax. Anim Behav 30:1084-1092

Grow L (1981) Burrowing behaviour in the crayfish, Cambarus diogenes diogenes Girard. Anim Behav 29:351-356

Günther HJ (1963) Untersuchungen zur Verbreitung und Ökologie von Uca tangeri an der SW-iberischen Küste. Z Morphol Ökol Tiere 53:242-310

Gusmão-Júnior JBL, Machado GBO, Costa TM (2012) Burrows with chimneys of fiddler crab Uca thayeri: construction, occurrence and function. Zool Stud 51:598-605

Hansell M (2007) Built by animals: the natural history of animal architecture. Oxford University Press, New York

Heatwole SJ, Christy JH, Backwell PRY (2018) Taking a risk: how far will male fiddler crabs go? Behav Ecol Sociobiol 72:82

Hunt J, Breuker CJ, Sadowski JA, Moore AJ (2009) Male-male competition, female mate choice and their interaction: determining total sexual selection. J Evol Biol 22:13-26

Jones DA (1972) Aspects of the ecology and behaviour of Ocypode ceratophthalmus (Pallas) and O. kuhlii de Haan (Crustacea: Ocypodidae). J Exp Mar Biol Ecol 8:31-43

Jones CG, Lawton JH, Shachak M (1994) Organisms as ecosystem engineers. Oikos 69:373-386

Kim TW, Choe JC (2003) The effect of food availability on the semilunar courtship rhythm in the fiddler crab Uca lactea (de Haan) (Brachyura: Ocypodidae). Behav Ecol Sociobiol 54:210-217

Kim TW, Christy JH (2015) A mechanism for visual orientation may facilitate courtship in a fiddler crab. Anim Behav 101:61-66

Kim TW, Christy JH, Choe JC (2004) Semidome building as sexual signaling in the fiddler crab Uca lactea (Brachyura: Ocypodidae). J Crust Biol 24:673-679

Kim TW, Christy JH, Choe JC (2006) The attractiveness of courtship signals increases with predation risk. Integr Comp Biol 46:E74-E74

Kim TW, Christy JH, Choe JC (2007) A preference for a sexual signal keeps females safe. PLoS ONE 2:e422

Kim TW, Christy JH, Dennenmoser S, Choe JC (2009) The strength of a female mate preference increases with predation risk. Proc R Soc B: Biol Sci 276:775-780

Kim TW, Kim TK, Choe JC (2010) Compensation for homing errors by using courtship structures as visual landmarks. Behav Ecol 21:836-842

Kim TW, Ryu HJ, Choi JB, Choe JC (2011) Tower construction by the manicure crab Cleistostoma dilatatum during dry periods on an intertidal mudflat. J Ethol 29:459-465

Kim TW, Lee JH, Choe JC (2017) Not all crabs are created equal: diverse evolutionary paths of female preferences for courtship structures in fiddler crabs (genus $U c a$ ). Behav Ecol Sociobiol $71: 33$

Koga T, Backwell PRY, Jennions MD, Christy JH (1998) Elevated predation risk changes mating behaviour and courtship in a fiddler crab. Proc R Soc B: Biol Sci 265:1385-1390

Kristensen E (2008) Mangrove crabs as ecosystem engineers; with emphasis on sediment processes. J Sea Res 59:30-43

Latruffe C, McGregor PK, Oliveira RF (1999) Visual signaling and sexual selection in male fiddler crabs, Uca tangeri. Mar Ecol Prog Ser 189:233-240

Linsenmair KE (1967) Konstruktion und signalfunktion der sandpyramide der reiterkrabbe, Ocypode saratan Forsk. (Decapoda, Brachyura, Ocypodidae). Zeitschrift für Tierpsychologie $24: 403-456$

Masunari S (2012) Hood construction as an indication of the breeding period of the fiddler crab Uca (Leptuca) leptodactyla Rathbun, 1898 (Decapoda, Ocypodidae) from Guaratuba Bay, southern Brazil. Crustaceana 85:1153-1169

Matsumasa M, Murai M, Christy JH (2013) A low-cost sexual ornament reliably signals male condition in the fiddler crab Uca beebei. Anim Behav 85:1335-1341

Matthews LH (1930) LXVI.-Notes on the fiddler-crab, Uca leptodactyla. Rathbun J Nat Hist 5:659-663

McHugh ML (2013) The chi-square test of independence. Biochem Med 23:143-149

Mokhlesi A, Kamrani E, Backwell PRY, Sajjadi M (2011) Study on the behaviour of two fiddler crabs, Uca sindensis and Uca annulipes (Decapoda: Ocypodidae), in Bandar Abbas, Iran. J Mar Biol Assoc UK 91:245-249

Mokhtari M, Ghaffar MA, Usup G, Cob ZC (2015) Determination of key environmental factors responsible for distribution patterns of fiddler crabs in a tropical mangrove ecosystem. PLoS ONE 10:e0117467

Montague CL (1980) A natural history of temperate Western Atlantic fiddler crabs (genus $U c a$ ) with reference to their impact on the salt marsh. Contrib Mar Sci 23:25-55

Müller W (1989) Untersuchungen zur akustisch-vibratorischen Kommunikation und Okologie tropischer und subtropischer Winkerkrabben. Zool Jahrb, Abt allg Zool Physiol Tiere 116:47-114

Muramatsu D (2009) To build or not to build—or to destroy burrow hoods in a population of Uca lactea. J Crust Biol 29:290-292

Muramatsu D (2010a) Temporary loss of a sexual signal (claw loss) affects the frequency of sand structure construction in the fiddler crab, Uca lactea. Ethol Ecol Evol 22:87-93

Muramatsu D (2010b) Sand structure construction in Uca lactea (De Haan, 1835) is related to tidal cycle but not to male or female densities. Crustaceana 83:29-37

Ng PKL, Sivasothi N (1999) A guide to the mangroves of Singapore II: animal diversity. Singapore Science Centre, Singapore

Nobbs M, Blamires SJ (2015) Spatiotemporal distribution and abundance of mangrove ecosystem engineers: burrowing crabs around canopy gaps. Ecosphere 6:1-13

Oliveira RF, McGregor PK, Burford FRL, Custodio MR, Latruffe C (1998) Functions of mudballing behaviour in the European fiddler crab Uca tangeri. Anim Behav 55:1299-1309

Peer N, Miranda NA, Perissinotto R (2015) A review of fiddler crabs (genus Uca Leach, 1814) in South Africa. Afr Zool 50:187-204

Perez DM, Christy JH, Backwell PRY (2016) Choosing a mate in a high predation environment: female preference in the fiddler crab Uca terpsichores. Ecol Evol 6:7443-7450

Peters HM (1955) Die Winkergebärde von Uca und Minuca (Brachyura) in vergleichend-ethologischer, ökologischer und morphologisch-anatomischer Betrachtung. Z Morphol Okol Tiere $43: 425-500$ 
Pope DS, Haney BR (2008) Interspecific signalling competition between two hood-building fiddler crab species, Uca latimanus and U. musica musica. Anim Behav 76:2037-2048

Powers LW, Cole JF (1976) Temperature variation in fiddler crab microhabitats. J Exp Mar Biol Ecol 21:141-157

Ribeiro PD, Christy JH, Rissanen RJ, Kim TW (2006) Males are attracted by their own courtship signals. Behav Ecol Sociobiol 61:81-89

Ribeiro PD, Christy JH, Nuñez JD, Iribarne OO (2016) Hood-building dynamics and mating mode in the temperate fiddler crab $\mathrm{Uca}$ uruguayensis Nobili, 1901. J Crust Biol 36:507-514

Rodríguez-Tovar FJ, Seike K, Curran HA (2014) Characteristics, distribution patterns, and implications for ichnology of modern burrows of Uca (Leptuca) speciosa, San Salvador Island, Bahamas. J Crust Biol 34:565-572

Rosenberg MS (2001) The systematics and taxonomy of fiddler crabs: a phylogeny of the genus Uca. J Crust Biol 21:839-869

Saher NU, Qureshi NA (2017) Construction of earthen structure as a sexual signals in the fiddler crabs. Int J Aquat Biol 5:40-46

Salmon M (1987) On the reproductive behaviour of the fiddler crab $U$ ca thayeri, with comparisons to $U$. pugilator and $U$. vocans: evidence for behavioural convergence. J Crust Biol 7:25-44

Salmon M, Hyatt G, McCarthy K, Costlow JD Jr (1978) Display specificity and reproductive isolation in the fiddler crabs, Uca panacea and U. pugilator. Z Tierpsychol 48:251-276

Schaedelin FC, Taborsky M (2009) Extended phenotypes as signals. Biol Rev 84:293-313

Shih HT, Mok HK, Chang HW (2005) Chimney building by male Uca formosensis Rathbun, 1921 (Crustacea: Decapoda: Ocypodidae) after pairing: a new hypothesis for chimney function. Zool Stud 44:242-251

Shih HT, Ng PKL, Davie PJF, Schubart CD, Türkay M, Naderloo R, Jones D, Liu MY (2016) Systematics of the family Ocypodidae Rafinesque, 1815 (Crustacea: Brachyura), based on phylogenetic relationships, with a reorganization of subfamily rankings and a review of the taxonomic status of $U c a$ Leach, 1814, sensu lato and its subgenera. Raffles B Zool 64:139-175

Slatyer RA, Fok ESY, Hocking R, Backwell PRY (2008) Why do fiddler crabs build chimneys? Biol Lett 4:616-618

Sturmbauer C, Levinton JS, Christy JH (1996) Molecular phylogeny analysis of fiddler crabs: test of the hypothesis of increasing behavioral complexity in evolution. Proc Nat Acad Sci 93:10855-10857

Takeshita F, Murai M, Matsumasa M, Henmi Y (2018) Multimodal signaling in fiddler crab: waving to attract mates is conditiondependent but other sexual signals are not. Behav Ecol Sociobiol $72: 140$

Thurman CL II (1984) Ecological notes on fiddler crabs of south Texas, with special reference to Uca subcylindrica. J Crust Biol 4:665-681

Thurman CL, Faria SC, McNamara JC (2013) The distribution of fiddler crabs $(U c a)$ along the coast of Brazil: implications for biogeography of the western Atlantic Ocean. Mar Biodivers Rec 6:e1

Tina FW, Jaroensutasinee M, Boonsanit P, Jaroensutasinee K (2017a) Chimneys of the fiddler crab Uca rosea (Tweedie, 1937) reduce the risk of losing burrows to intruders. Crustaceana 90:589-600

Tina FW, Jaroensutasinee M, Jaroensutasinee K (2017b) Burrow excavation and mudballing behaviour of the fiddler crab Uca annulipes (H. Milne Edwards, 1837) from southern Thailand. Crustaceana 90:735-743
Tina FW, Jaroensutasinee M, Keeratipattarakarn K, Jaroensutasinee J (2018a) Sex and burrow/chimney ownership affecting time allocation for surface activities in Uca rosea (Tweedie, 1937) (Brachyura, Ocypodidae). Crustaceana 91:5162

Tina FW, Jaroensutasinee M, Keeratipattarakarn K, Jaroensutasinee K (2018b) Surface mating influences chimney/burrow characteristics of Uca rosea (Tweedie, 1937) (Brachyura, Ocypodidae) in southern Thailand. Crustaceana 91:311-320

Tweedie MWF (1937) On the crabs of the family Ocypodidae in the collection of the Raffles Museum. Raffles B Zool 13:140-170

von Hagen HO (1968) Studien an peruanischen Winkerkrabben (Uca). Zool Jahr, Abt allg Zool Physiol Tiere 95:395-468

von Hagen HO (1970) Verwandtschaftliche Gruppierung und Verbreitung der Karibischen Winkerkrabben (Ocypodidae, Gattung Uca). Zool Meded 44:217-235

Wada K (1984) Barricade building in Ilyoplax pusillus (De Haan) (Crustacea: Brachyura). J Exp Mar Biol Ecol 83:73-88

Wada K (1994) Earthen structures built by Ilyoplax dentimerosa (Crustacea, Brachyura, Ocypodidae). Ethology 96:270-282

Wada K, Murata I (2000) Chimney building in the fiddler crab Uca arcuata. J Crust Biol 20:505-509

Wada K, Kosuge T, Trong PD (1998) Barricade building and neighbor burrow-plugging in Ilyoplax ningpoensis (Brachyura, Ocypodidae). Crustaceana 71:663-671

Weis JS, Weis P (2004) Behavior of four species of fiddler crabs, genus Uca, in southeast Sulawesi, Indonesia. Hydrobiologia 523:47-58

Williams DD, Williams NE, Hynes HBN (1974) Observations on the life history and burrow construction of the crayfish Cambarus fodiens (Cottle) in a temporary stream in southern Ontario. Can J Zool 52:365-370

Wolfrath B (1992) Burrowing of the fiddler crab Uca tangeri in the Rio Formosa in Portugal and its influence on sediment structure. Mar Ecol Prog Ser 85:237-243

Yamaguchi T (1971) Courtship behaviour of a fiddler crab, Uca lactea. Kumamoto J Sc 10:13-37

Yamaguchi T (2001) The breeding period of the fiddler crab, Uca lactea (Decapoda, Brachyura, Ocypodidae) in Japan. Crustaceana 74:285-294

Yamaguchi T, Henmi Y, Tabata S (2005) Hood building and territory usage in the fiddler crab, Uca lactea (De Haan, 1835). Crustaceana 78:1117-1141

Zhu Z, Kim TW, Choe JC (2012) Is female preference for large sexual ornaments due to a bias to escape predation risk? BMC Evol Biol 12:1

Zucker N (1974) Shelter building as a means of reducing territory size in the fiddler crab, Uca terpsichores (Crustacea: Ocypodidae). Am Midl Nat 91:224-236

Zucker N (1978) Monthly reproductive cycles in three sympatric hood building tropical fiddler crabs (genus $U c a$ ). Biol Bull 155:410-424

Zucker N (1981) The role of hood-building in defining territories and limiting combat in fiddler crabs. Anim Behav 29:387-395

Publisher's Note Springer Nature remains neutral with regard to jurisdictional claims in published maps and institutional affiliations. 